\title{
A propagação de novos modos de regulação no sistema educacional brasileiro: o Plano de Ações Articuladas e as relações entre as escolas e a União ${ }^{1}$
}

Marisa Ribeiro Teixeira Duarte* , Déborah Saib Junqueira**

\section{Resumo}

A investigação analisou as relações intergovernamentais - conhecidas como regime de colaboração entre os entes federados - pela via do mecanismo de planejamento educacional presente no sistema educacional brasileiro o "Plano de Ações Articuladas” (PAR), elaborado pelo Ministério da Educação. A abordagem acha-se associada à chamada sociologia das regulações sociais e constituiu chave de leitura do Plano de Ações Articuladas de Prefeitura Municipal e de 93 Planos de Desenvolvimento, construídos por escolas de redepública municipal. Os resultados obtidos indicam a associação do planejamento desenvolvido no âmbito de cada escola e do município com os projetos educacionais formulados e financiados pela União. Expõem, também, tensões existentes na articulação das demandas formuladas pelos atores situados nas escolas e as diretrizes de políticas públicas. 0 estudo conclui que o PAR constitui importante mecanismo de efetivação do regime de colaboração, mediante a associação da regulação por desempenho e burocrático-profissional do sistema educacional brasileiro.

\author{
* Professora associada \\ do Departamento de \\ Administração Escolar e do \\ Programa de Pós- Graduação \\ da Faculdade de Educação \\ da Universidade Federal de \\ Minas Gerais (UFMG), Brasil. \\ mmduarte@ufmg.br.
}

** Pedagoga e professora de rede pública municipal de Belo Horizonte, MG, Brasil. deborahsaib@gmail.com.

\section{Palavras-chave}

políticas públicas em educação; regulação dos sistemas educacionais; gestão da educação.

1. Este estudo contou com o apoio financeiro do INEP/ MEC e compõe o programa de estudos: "Observatório da gestão municipal da educação" em desenvolvimento no Grupo de Pesquisa de Política e Administração de Sistemas de Ensino. 


\title{
The propagation of new modes of regulation in the Brazilian educational system: Articulated Actions Plan and the relationships between schools and the Federal Government
}

\begin{abstract}
This research addresses the joint intergovernmental mechanism present in the Brazilian educational system, the "Articulated Actions Plan" (AAP) prepared by the Ministry of Education. The approach was linked to the so-called sociology of social regulations and was key to the interpretation of the Articulated Action Plan from the the City Council and 93 Development Plans formulated by municipal schools. The results indicate the association between the planning developed within each school and the municipality with the educational projects formulated and funded by the federal government. It also exposes tensions in articulating the demands made by players from the schools and the public policies directives. The study concludes that the AAP is an important mechanism for ensuring a system of collaboration, upon the performance and bureaucratic-professional regulation of the Brazilian educational system.
\end{abstract}

Key words public policies in education; regulation of educational systems; management education. 


\section{União.}

\section{Indicadores de qualidade na educação: aferição por resultados}

A partir da segunda metade da década de 1990, mediante testes padronizados de abrangência nacional e coleta mais sistematizada de dados sobre condições de oferta na Educação Básica, incorporavam-se ao processo decisório em políticas públicas no campo educacional informações propícias à compreensão de fatores intervenientes sobre as práticas educacionais e sobre o desempenho dos estudantes. A política educacional do período fundamentava-se em três aspectos: revalorização da racionalidade técnica; ênfase no ensino fundamental; valorização dos resultados educacionais e das evidências trazidas à tona pela emergência das avaliações sistêmicas (Franco Alves; Bonamino, 2007, p. 1000).

Duarte (2005, p.835) assinalava que a implementação do Fundo de Desenvolvimento do Ensino Fundamental e Valorização do Magistério - Fundef²-, introduzia no sistema educacional brasileiro, lógicas intersistêmicas de ação competitivas, reguladas pelo mecanismo de distribuição dos recursos já vinculados à manutenção e desenvolvimento do ensino. Entretanto, para a autora, o mecanismo redistributivo do Fundef, incapaz de impulsionar melhorias na qualidade da educação ofertada (seja no que se refere a suas condições materiais, seja quanto a procedimentos de ensino), era de fundamental importância para o atendimento de demandas por acesso, sem o aporte de novos recursos.

Oliveira (2007) considera a qualidade da/na educação como uma preocupação recente no meio educacional brasileiro, pois, até a década de 1990, tal questão era pouco visível diante dos grandes índices de exclusão gerados pela reprovação e pela evasão escolares. 0 autor afirma, sem entrar no mérito do significado que o termo assumiu na atualidade, que a qualidade passou a ser mais discutida com a ampliação do atendimento escolar. Para esse autor, desigualdades e exclusão escolar persistem no sistema educacional brasileiro, mas já não são as mesmas que ocorriam em um passado não tão distante. Os desafios pós-década de 1990 seriam outros:

Atribuo importância significativa à

2. 0 Fundo de Manutenção e Desenvolvimento do Ensino Fundamental e de Valorização do Magistério, que vigorou entre 1997 e 2005, incentivou o crescimento das matrículas no Ensino Fundamental regular e a crescente municipalização desta etapa da Educação Básica mediante o atrelamento de recursos a serem repassados à matrícula (Pinto, 2007, p. 879). 0 Fundeb (Fundo de Manutenção e Desenvolvimento da Educação Básica), vigorando desde 2006, passou a incluir outras etapas e modalidades da educação básica na distribuição dos recursos subvinculados. 
universalização do acesso ao ensino fundamental, posto que esta faz com que "as contradições mudem de lugar", passando a concentrar-se na expansão das etapas posteriores a este e na qualidade da educação básica, notadamente do ensino fundamental. (Oliveira, 2007, p.676).

Franco, Alves e Bonamino (2007, p. 990-992) caracterizam a última década do século XX como um período no qual ocorreu no Brasil a emergência e a difusão do significado do termo qualidade da/na educação, relacionada ao desempenho acadêmico dos alunos medidos por testes nacionais padronizados. Relatam que a institucionalização do Sistema de Avaliação da Educação Básica (Saeb) fortaleceu essa significação a partir da aferição regular e recorrente do rendimento na educação pública e privada. Para esses autores, o recém-elaborado Índice de Desenvolvimento da Educação Básica - IDEB -, indicador sintético de fluxo e desempenho, proposto no Plano de Desenvolvimento da Educação em 2007 - tem como princípio básico o fato de que a qualidade da educação pressupõe que o aluno aprenda e passe de ano.

Para autores como Oliveira (2007, p. 686), sem entrar no mérito da discussão que o termo qualidade adquire, a democratização do acesso e a regularização do fluxo colocaram pela primeira vez ao sistema escolar brasileiro o desafio de assumir a responsabilidade pelo aprendizado de todas as crianças e jovens. A associação entre aferição da aprendizagem medida por testes nacionais padronizados e qualidade da educação foi também apreendida como manifestação do direito à educação básica, entendido como direito de aprendizagem.

0 direito à educação não pode ser confundido com o direito ao acesso à escola, traduzido pelo aumento das estatísticas dos alunos matriculados, apenas. Este acesso precisa vir acompanhado do compromisso com a aprendizagem dos estudantes e com seu direito de acesso ao conhecimento acumulado (Sordi; Ludke, 2009, p. 328).

Em outras palavras, esse estudo observa que, a partir da década de 1990, uma concepção de qualidade da educação, associada às medidas de rendimento do estudante, acha-se presente na literatura educacional, nos debates e nas decisões para a formulação de políticas educacionais no País. Medir o rendimento do estudante passou a significar aferir a qualidade da educação. Para autores como Ro- 
sanvallon (2008, p. 104-110), as mudanças sociais e econômicas em curso têm, nas medidas de aferição da qualidade, função sociopolítica central. Na atualidade, não podem ser apreendidas apenas como evolução de setores econômicos (serviços, novas tecnologias, etc.), mas, sim, profundamente determinadas por uma "economia da particularidade”. Essa noção, segundo o autor, permite a elaboração de um referente analítico capaz de apreender todo um conjunto de mudanças, tanto da ordem do consumo, da produção, da organização do trabalho. Acrescenta o autor, ainda, que a amplitude das mudanças ocorridas no modo de produção capitalista acha-se, também, ligada à emergência de uma sociedade da particularidade ${ }^{3}$, ou seja, a emergência de outras modalidades de constituição das relações sociais e das identidades coletivas. É nesse novo contexto que a avaliação adquire maior centralidade, pois indivíduos-consumidores buscam parâmetros de comparação de bens e serviços de que necessitam.

No campo educacional, métodos e processos vão se diversificando, tanto quanto as identidades e os procedimentos profissionais dos que atuam nos sistemas de ensino. Formas situadas de agir são portadoras de valores diversos e nutrem-se de interpretações do social e das redes de relações que as estruturam politicamente. A regulação normativa do sistema educacional brasileiro, que reconhece como entidade federativa os municípios, possibilita a estes a formulação legislativa no âmbito de suas competências, especialmente na normatização da Educação Infantil e da parte curricular diversificada. No entanto, a difusão de testes padronizados de aferição da aprendizagem dos alunos e dos procedimentos de avaliação de desempenho dos profissionais dissemina ações e preocupações voltadas para os resultados. Ou seja, a natureza profundamente política das regulações pode conduzir a melhorar os resultados do conjunto do sistema, mas a ênfase posta nos resultados pode gerar, também, efeitos de performatividade (Ball, 2002, 2004).

Essa sociologia das regulações sociais aponta para a emergência de novas formas de sociabilidade política (Maroy, 2005, 2008; Rosanvallon, 2008), em que modos de regulação pós-burocráticos dos sistemas educativos se disseminam em um país onde a regulamentação de seu sistema educacional é recente e sujeita a diversas alterações. No Brasil convivem mais de 2.000 sistemas municipais de ensino, 26 sistemas estaduais (além do Distrito

3. Para 0 sociólogo, não se trata da redução do coletivo ao individual, ou a uma simples desagregação das relações anteriores. Não é uma sociedade que se desfaz, mas o modo de composição do social que está se transformando (Rosanvallon, 2008, p. 108). 
Federal), governados por um número diversificado de partidos políticos, cujos agentes detêm autonomia político administrativa e atribuições privativas ou concorrentes. A coordenação sistêmica requer engenhosidade e capacidade de intervenção dos poderes mais centrais - a União e os estados subnacionais4.

Segundo Barroso (2005, p. 727), “a difusão, no domínio educativo, do termo 'regulação' está associada, em geral, ao objetivo de consagrar, simbolicamente, outro estatuto de intervenção do Estado à condução das políticas públicas." O termo regulação por desempenho significaria algo mais flexível na definição dos processos e um controle mais rigoroso na avaliação da eficiência e da eficácia dos resultados, ao passo que a "regulamentação", proveniente do modelo racional burocrático, estaria centrada no controle dos procedimentos, sem dar relevância às questões de qualidade e eficácia dos resultados.

Maroy $(2006,2008)$ argumenta sobre a emergência, na atualidade, de novos modos de regulação dos sistemas educacionais. Um primeiro, denominado regulação por resultado, fundamenta-se no aumento da legitimidade da avaliação sobre os sistemas educacionais. 0 que importa nesse novo modelo de regulação, segundo esse autor, é a valorização dos resultados, a busca da eficácia; procedimentos e regras são submetidos à aferição dos resultados obtidos. Pretende-se um controle social pela via da responsabilização, em que a avaliação do efeito alcançado adquire centralidade política. A esta se contrapõe a regulação de matriz burocrática profissional, hegemônica nos sistemas educacionais europeus, em que uma racionalidade instrumental prescritiva enfatiza meios necessários para atingir as finalidades pretendidas 5 .

4. Cury (2008) destaca a forma histórica de que se revestiu nosso federalismo como um dos obstáculos à constituição de um sistema educacional nacional. Seu artigo introduz três questões fundamentais às políticas públicas em educação: "a convivência de dois sistemas de educação básica, a inexistência de sistema educacional nacional e a desarticulação das políticas intergovernamentais”. Às duas últimas, relacionadas às relações intergovernamentais, procuramos indicar os novos caminhos em construção. 5. Um segundo modo de regulação é denominado por Maroy (2008) de regulação por quase-mercado. É caracterizado por privilegiar a atuação de operadores privados sobre a educação por meio do crescente incentivo do Estado à oferta privada dos serviços educacionais nos sistemas de ensino.

\section{Planos de educação e a regulação do sistema educacional brasileiro}

O Plano de Desenvolvimento da Educação PDE - é um documento governamental, divulgado em 2007, que procura articular programas e ações em desenvolvimento no Ministério da Educação MEC (Saviani, 2007). É a partir de sua divulgação e da promulgação do Decreto nํ 6.094, nesse mesmo ano, que os entes da federação podem pactuar-se para o cumprimento das diretrizes e metas nele des- 
critas (Brasil,2010, p.45), mediantea elaboraçãodePlano(s) deAção(ões) Articulada(s)PAR. Esse mecanismo é reconhecido pelo Ministério como procedimento que inaugura um novo regime de colaboração $0^{6}$ entre os entes federados.

Conforme análise de Weber (2008, p. 312-315), o PDE e o PAR fazem parte de um projeto central da União que busca induzir a participação dos entes governamentais (estados e municípios) e suas instâncias educativas (escolas) em ações visando à melhoria da qualidade. Esse mecanismo de indução incentiva-os à participação mediante o diagnóstico de necessidades educacionais e o oferecimento de recursos. Para essa autora, o PDE sistematiza projetos do Ministério da Educação e busca concretizá-los nas diferentes regiões do País, como requisito de ação sistêmica da União.

Consideramos, entretanto, como hipótese analítica, que o PDE é um documento que expõe as diretrizes federais de regulação (Barroso, 2005, p. 730) do sistema educacional brasileiro e formula mecanismos de articulação e coordenação das ações intergovernamentais no âmbito do Ministério da Educação. Neste referente analítico inexiste um macroator capaz de controlar, mediante um processo racional e hierárquico, os sistemas locais de ensino. Pelo contrário, a regulação dos sistemas educacionais resultaria de um complexo sistema de multicoordenação, com a participação de diferentes atores em interação desigual (Barroso, 2005; Maroy, 2008). Barroso (2006, p. 63) atenta, com fundamento em Jessop (2003), para a importância de "meta estruturas de coordenação intergovernamental, que assegurem em última instância a legitimação de diferentes modos de regulação". E é nesse sentido que orientamos a análise de novos dispositivos contidos no PDE, divulgado em 2007, especialmente a singularidade do Plano de Ações Articuladas - PAR.

\section{Contexto e processo da elaboração do Plano de Ações Articuladas}

No mesmo ano em que divulga o PDE, o governo federal dispõe sobre a implementação do Plano de Metas Compromisso Todos pela Educação, por meio do Decreto no 6094/077 em regime de colaboração com os municípios, o Distrito Federal, os estados e com a participação das famílias e da comunidade. Neste Plano de Metas, encontra-se proposição para a formulação, pelos demais sistemas

6. A Constituição Brasileira determina à União, aos Estados, ao Distrito Federal e aos Municípios que organizem, em regime de colaboração, seus sistemas de ensino (art. 211, CF); entretanto, normas reguladoras desse regime não foram estabelecidas por lei complementar (ver a respeito: Cury, 2008).

7. Solano $(2010, p .8)$ informa que empresários brasileiros e organismos internacionais foram protagonistas na estruturação das metas incorporadas nas diretrizes do Decreto no 6094/07 - Plano de Metas Compromisso Todos pela Educação. Saviani (2007, p.1253) destaca a lógica de ação do setor empresarial no que tange à educação básica. 
de ensino, de seus Planos de Ações Articuladas - PAR. Todos os entes que elaborarem o seu PAR tornam-se passíveis de receber assistência técnica e/ou financeira (Brasil, 2009b,p.3) e são estimulados a operacionalizar as diretrizes normativamente estabelecidas no Plano de Metas. Iniciam-se, assim, processos de articulação e coordenação de ações, territorialmente situadas em torno de resultados preestabelecidos, especialmente aqueles referentes à melhoria do desempenho educacional medido pelo IDEB.

O esquema geral de procedimentos para formulação do Plano de Ações Articuladas - PAR - pelos estados subnacionais e municípios acha-se formatado pelo Ministério da Educação (Quadro1):

\section{Quadro 01 - Sequência de procedimentos para elaboração de Planos de Ações Articuladas}

\begin{tabular}{|c|c|}
\hline $1^{\circ}$ & Adesão do ente federado ao Plano de Metas Compromisso Todos pela Educação. \\
\hline $2^{\circ}$ & Composição da equipe técnica local. \\
\hline $3^{\circ}$ & $\begin{array}{l}\text { Análise das informações pré-qualificadas disponibilizadas pelo MEC/ INEP: } \\
\text { dados da unidade (município) e dados demográficos e educacionais. }\end{array}$ \\
\hline $4^{\circ}$ & Respostas às questões pontuais. \\
\hline $5^{\circ}$ & $\begin{array}{l}\text { Realização do diagnóstico local a partir da a do instrumento composto pelas dimensões, } \\
\text { áreas e indicadores. }\end{array}$ \\
\hline $6^{\circ}$ & Levantamento dos indicadores com baixa pontuação. \\
\hline $7^{\circ}$ & $\begin{array}{l}\text { Elaboração do Plano de Aç̃es Articuladas - PAR, buscando a melhoria dos indicadores } \\
\text { com baixa pontuação.Satisfazer sua curiosidade em relação a várias realidades sociais }\end{array}$ \\
\hline
\end{tabular}

Fonte: Brasil, 2008b, p. 5

Planos de Ações Articuladas - PAR - seriam iniciados a partir de um diagnóstico - análise de informações pré-qualificadas (Quadro 1) - realizado pelas equipes técnicas das secretarias locais sobre a situação da educação nos municípios ou no estado subnacional. Esse diagnóstico acha-se estruturado em quatro grandes dimensões: 
1. Gestão educacional;

2. Formação de professores e profissionais de serviço e apoio escolar;

3. Práticas pedagógicas e Avaliação;

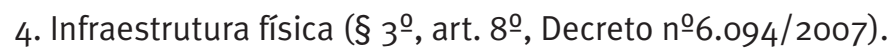

Essas dimensões, por sua vez, encontram-se subdivididas em áreas de atuação as quais possuem indicadores de qualidade, que explicitam as metas a serem alcançadas. Esses indicadores de qualidade acham-se delineados nas 28 diretrizes que compõem o Decreto no 6.094/2007.

Desde essa etapa diagnóstica inicial, o MEC disponibiliza aos gestores municipais de educação e técnicos locais um módulo no Sistema Integrado de Planejamento de Orçamento e Finanças do Ministério da Educação - Simec. Nesse módulo, encontram-se os procedimentos operacionais para a realização do diagnóstico e a formulação do PAR, além do monitoramento de suas ações (Brasil, 2009a, p. 2). Na fase de diagnóstico, esse instrumento eletrônico - módulo do Simec - permite que as equipes locais avaliem, mediante a pontuação de um a quatro, a situação do município diante de cada um dos indicadores já propostos. Os indicadores que obtiverem menor pontuação (um ou dois) deverão compor o PAR e a estes são atribuídas ações pré-qualificadas divididas em subações, que visem à melhoria daquele indicador.

É importante destacar que um leque, de ações e subações contidas no Simec, se encontra previamente definido pelo MEC, cabendo às equipes técnicas locais escolher aquelas que melhor satisfaçam suas necessidades, com fundamento no diagnóstico efetuado, para o alcance da melhoria dos indicadores que obtiveram baixa pontuação:

Nesse guia [prático de ações] estão todos os programas disponibilizados pelo Ministério da Educação e suas autarquias, com ações de assistência técnica e/ou financeira do MEC e que podem ser solicitadas pelos municípios em seus respectivos planos. (Brasil, 2009c, p. 2)

\section{Plano de Ações Articuladas de uma prefeitura municipal: aspectos de seu conteúdo}

A proposta apresentada pela Prefeitura Municipal de X - PBX - abrangeu as quatro dimensões previstas pelo Ministério da Educação brasileiro ${ }^{8}$
8. PAR/PBX, elaborado em 2007, disponível em: http:// portal.mec.gov.br/index.php?option=com_content\&view $=$ article\&id=147\&ltemid=367. Acesso em: 16/03/2011. As áreas de atuação descritas neste estudo abrangem aquelas selecionadas pela equipe técnica da Prefeitura Municipal. 
e acha-se subdividida em nove áreas de atuação - Quadro 2, cada uma contendo indicadores de resultados a serem obtidos.

\begin{tabular}{|c|c|}
\hline DIMENSÕES & ÁREAS DE ATUAÇÃO SELECIONADAS PELA PBX \\
\hline \multirow{3}{*}{1 - GESTÃO EDUCACIONAL } & $\begin{array}{l}1.1 \text { - Gestão Democrática: Articulação e Desenvolvimento dos } \\
\text { Sistemas de Ensino; }\end{array}$ \\
\hline & $\begin{array}{l}\text { 1.2 - Desenvolvimento da Educação Básica: ações que visem } \\
\text { a sua universalização, à melhoria da qualidade do ensino e } \\
\text { da aprendizagem, assegurando a equidade nas condições de } \\
\text { acesso, permanência e conclusão na idade adequada; }\end{array}$ \\
\hline & 1.3 - Comunicação com a sociedade. \\
\hline \multirow{3}{*}{$\begin{array}{l}2 \text { - FORMAÇÃO DE PROFESSORES } \\
\text { E DE PROFISSIONAIS DE } \\
\text { SERVIÇOS E APOIO ESCOLAR }\end{array}$} & 2.1 - Formação inicial de Professores da Educação Básica; \\
\hline & $\begin{array}{l}\text { 2.2- Formação de Professores da Educação Básica para } \\
\text { atuação em educação especial, escolas do campo, } \\
\text { comunidades quilombolas ou indígenas; }\end{array}$ \\
\hline & 2.3 - Formação do Profissional de Serviços e Apoio Escolar. \\
\hline \multirow[b]{2}{*}{$\begin{array}{l}3 \text { - PRÁTICAS PEDAGÓGICAS } \\
\text { E AVALIAÇÃOO }\end{array}$} & 3.1. - Elaboração e organização das práticas pedagógicas; \\
\hline & $\begin{array}{l}3.2 \text { - Avaliação da aprendizagem dos alunos e tempo para } \\
\text { assistência individual/coletiva aos alunos que apresentam } \\
\text { dificuldade de aprendizagem. }\end{array}$ \\
\hline $\begin{array}{l}4 \text { - INFRAESTRUTURA FÍSICA E } \\
\text { RECURSOS PEDAGÓGICOS }\end{array}$ & 4.1 - Instalações físicas gerais. \\
\hline
\end{tabular}

\section{Quadro 2 - Áreas de atuação selecionadas pela PBX, de acordo com as dimensões previstas no Simec}

Fonte: PAR/ PBX (2007) 
As ações selecionadas pela PBX relativas à área “Gestão Democrática: articulação e desenvolvimento dos Sistemas de Ensino"(dimensão “Gestão Educacional”) são quatro, sendo que cada uma contém a descrição do resultado pretendido(PAR/ PBX, 2007):

1. Formação continuada dos conselheiros escolares:

Resultado esperado: conselho escolar atuante, que zele pelo cumprimento das normas e que auxilie a escola no planejamento de suas atividades e no acompanhamento do desenvolvimento dos alunos.

Subação relacionada: formação de 300 conselheiros escolares.

2. Incentivo à atuação do Conselho Municipal de Educação - CME: Resultado esperado: CME atuante e representativo, que zele pelo cumprimento das normas, que auxilie a Secretaria Municipal de Educação (SME) -- no planejamento municipal da educação e no acompanhamento das avaliações educacionais.

Subações relacionadas: a) elaboração de projeto de lei para escolha de conselheiros municipais; b) produção de 380 mil cartilhas/periódicos sobre o CME.

3. Promoção da implantação do Projeto Pedagógico (PP) nas escolas da rede, considerando as particularidades de cada estabelecimento de ensino; Resultado esperado: não descrito.

4. Adequação dos critérios de escolha de diretores, fundamentados nos princípios democráticos.

Resultado esperado: escolha da direção das escolas por critérios que considerem, também, experiência profissional, mérito e desempenho.

Subações relacionadas: a) elaboração de norma sobre escolha de dirigentes escolares; b) formação de 180 diretores escolares em cursos de aperfeiçoamento e de especialização.

Tanto as ações relacionadas à formação de conselheiros escolares quanto as de incentivo à atuação do Conselho Municipal de Educação têm por pressuposto a atuação desses órgãos nas atividades de supervisão - zelar pelo cumprimento - das ações e das normas educacionais. Esta vertente de ação os reconhece como órgãos 
de participação da sociedade e auxiliares do poder executivo, mas o planejamento efetuado silencia quanto ao reconhecimento como órgãos de deliberação no âmbito de sua competência. A partir da influência do que se convencionou chamar de gerencialismo - new public management -, a formatação da ação pública dirige-se para a construção de mecanismos de responsabilização (accountability). A ênfase política e a sociabilidade pretendida dirigem-se para a busca de maior eficiência mediante o uso adequado dos recursos financeiros.

Por sua vez, ao associar a escolha de dirigentes escolares aos critérios de experiência profissional, mérito e desempenho - indicador quatro -, o PAR-PBX avaliou que os procedimentos atuais de eleição direta dos dirigentes escolares pela comunidade são insuficientes, e apontou para a necessidade de normas e processos formativos abrangendo critérios de escolha de matriz profissional. Nesse caso, a solução aventada contém formulação da esfera de autonomia do ente federado e o seu diagnóstico sobre o que foi considerado como situação a ser enfrentada para a gestão do sistema municipal.

Nas ações selecionadas pela equipe técnica da Prefeitura de $X$, a preocupação relativa ao desenvolvimento da qualidade dos serviços que ofertam à educação básica relaciona-se a dois tipos de ações: uma relativa à ampliação do atendimento à comunidade escolar (ampliação do tempo dos alunos na escola); outra, relacionada ao monitoramento do desempenho escolar, com ampla divulgação dos resultados das avaliações mediante testes padronizados. Alguns desses programas e projetos acham-se em implementação no município e, no PAR, pretende-se obter recursos complementares.

No plano formulado localmente, a ampliação dos tempos escolares envolveria a reestruturação pedagógica da rede municipal por meio de parcerias com instituições de ensino superior, ONG's, instituições públicas e privadas, institutos e fundações. Por sua vez, o monitoramento do desempenho escolar será efetuado mediante elaboração de sistema próprio de avaliação educacional e pela produção de material para divulgação do resultado dos alunos à sociedade, profissionais da educação e comuni-

9. Em 1993 foi divulgado em Minas Gerais o "Pacto de Minas pela Educação”, sob a inspiração das diretrizes formuladas na Conferência Mundial de Jontien/Tailândia. As diretrizes desse movimento chamavam a atenção para o engajamento e a incorporação de novos atores na busca de uma educação de qualidade para todos. É preciso destacar que essa abordagem foi criticada pelo partido de oposição no período - Partido dos Trabalhadores - como uma abordagem neoliberal. dade escolar. Nesse sentido, o PAR elaborado pela equipe técnica da cidade $X$ projeta que a ampliação da jornada escolar abrangeria atividades voluntárias ou um envolvimento proativo de empresas e/ ou organizações sociais nas atividades educativas. Em paralelo, o poder público declara-se como responsável pela avaliação de resultados. Tratam- 
-se, a nosso ver, de procedimentos que contribuem para a formação de pessoas e/ ou grupos mobilizados e capazes de realizar ações que resolvam ou minimizem situações-problema. O engajamento cívico traduzir-se-ia por cidadãos envolvidos em projetos sociais, que substituam ou complementem a atuação do poder público. O PAR elaborado pela cidade $X$ contém, também, expectativas de divulgação dos resultados e desse modo medidas voltadas para a regulação por desempenho das escolas municipais.

Para a área de atuação relacionada às práticas pedagógicas, um dos indicadores, intitulado “Estímulo às práticas pedagógicas fora do espaço escolar”, prevê a promoção e a execução de práticas pedagógicas alternativas, cujos resultados esperados seriam “práticas pedagógicas promovidas” (PAR/PBX, 2007). Na justificativa para esta ação, são elencadas práticas pedagógicas as mais diferenciadas, com ênfase nas atividades já existentes nas escolas municipais. Essas práticas pedagógicas alternativas são consideradas atividades culturais fora do ambiente escolar, e justificadas como promotoras da integração com a comunidade do entorno das escolas:

Justificativa: as escolas estimulam e dão condições para a realização de práticas pedagógicas fora do espaço escolar. (Exemplo: atividades culturais como visitas a museus, cinema, teatro, exposições, entre outras; atividades de educação ambiental, como passeios ecológicos, visitas à estação de tratamento de água e esgoto, aterro sanitário, entre outras; atividades de integração com a comunidade do entorno -PAR/PBX, 2007)

Ao associar a proposição de ações de ampliação do tempo escolar com a participação de outros atores, diversos dos profissionais da educação, o planejamento municipal orienta-se, simultaneamente, para o atendimento das demandas em torno da extensão dos tempos escolares, porém pela via de atividades em que a prestação direta dos serviços, pelo poder público e por profissionais de magistério, é relativizada.

No PAR-PBX encontra-se, ainda, ação ${ }^{10}$ relativa à implantação e à implementação de Projeto Pedagógico em cada escola, com o objetivo de melhoria de fatores de gestão internos a ela. No sistema de elaboração do PAR, a subação vinculada a esta ação envolve a elaboração,

10. Esta ação está contida na dimensão e na área - Gestão Educacional; Gestão Democrática: articulação e desenvolvimento dos sistemas de ensino - e relacionada ao indicador: "existência de projeto pedagógico nas escolas e grau de participação dos professores e do conselho escolar na sua elaboração". 
pelas escolas, de seu Plano de Desenvolvimento - PDE-Escola. E, no Guia Prático de Ações do Ministério (Brasil, 2009c), a elaboração do PDE-Escola pelas escolas dos municípios justifica-se pela busca de melhoria dos resultados educacionais medidos pelo IDEB. Porém, segundo esse guia, mesmo as escolas municipais que não apresentam baixo IDEB poderiam implementar a metodologia de planejamento estratégico do PDE-Escola; nesse caso, o projeto é realizado sem recebimento de recursos federais (Brasil, 2009c, p. 9).

A análise dos dispositivos e dos procedimentos elencados no Plano de Ações de um município específico revela o nível de detalhamento dos procedimentos previstos e sua articulação com os produtos desejáveis para alcançar os objetivos de melhoria dos resultados educacionais medidos pelo IDEB. Com esse mecanismo, o poder central da federação objetiva conseguir maior coerência e coesão na implementação local de projetos e programas diversos. A sistemática de formulação do PAR, pela via do ambiente virtual, é capaz de orientar a interpretação dos parâmetros institucionais pelos quais os atores locais devem agir, especialmente nos municípios de pequeno e médio porte, sem equipes técnicas e profissionais com formação adequada.

\section{Indução para a implementação local de programas formulados centralmente}

Azevedo (2002) e Duarte (2002) já comentavam sobre os mecanismos de indução da União sobre os governos locais. Azevedo (2002) destacava que esse movimento, em função da iniciativa do Programa Dinheiro Direto na Escola, promovia a gestão por projetos no âmbito de cada escola. Duarte (2002), por sua vez, ao analisar as transferências voluntárias da União, destacou o papel indutor nelas contido, por estarem associadas a programas formulados centralmente. A análise do PAR-PBX explicita a continuidade desse mecanismo de regulação do sistema educacional federativo e sua disseminação tanto nas relações intergovernamentais como nas relações com

11. A denominação utilizada no SIMEC é "Formação de professores da educação básica para atuação em educação especial, escolas de campo, comunidades quilombolas ou indígenas". 


\section{Quadro 3 - Detalhamento dos programas do Ministério da Educação constantes na dimensão dois do PAR}

\begin{tabular}{|c|c|c|c|}
\hline INDICADOR & AÇÃO & RESULTADO ESPERAD0 & $\begin{array}{l}\text { PROGRAMA DO MEC } \\
\text { REQUERIDO }\end{array}$ \\
\hline $\begin{array}{l}\text { Qualificação dos } \\
\text { professores que atuam } \\
\text { nas creches }\end{array}$ & $\begin{array}{l}\text { Assegurar o acesso à } \\
\text { formação continuada } \\
\text { a todos os professores } \\
\text { que atuam nas creches. }\end{array}$ & $\begin{array}{l}\text { Garantir a qualificação } \\
\text { dos profissionais para } \\
\text { atuarem na Educação } \\
\text { Infantil. }\end{array}$ & $\begin{array}{l}\text { UAB - Universidade } \\
\text { Aberta do Brasil - } \\
\text { Pedagogia }\end{array}$ \\
\hline $\begin{array}{l}\text { Qualificação dos } \\
\text { professores que atuam } \\
\text { na pré-escola }\end{array}$ & $\begin{array}{l}\text { Assegurar o acesso à } \\
\text { formação continuada } \\
\text { a todos os professores } \\
\text { que atuam nas creches. }\end{array}$ & $\begin{array}{l}\text { Garantir a qualificação } \\
\text { dos profissionais para } \\
\text { atuarem na Educação } \\
\text { Infantil. }\end{array}$ & $\begin{array}{l}\text { UAB - Universidade } \\
\text { Aberta do Brasil - } \\
\text { Pedagogia }\end{array}$ \\
\hline $\begin{array}{l}\text { Qualificação dos } \\
\text { professores que } \\
\text { atuam em educação } \\
\text { especial, escolas do } \\
\text { campo, comunidades } \\
\text { quilombolas ou } \\
\text { indígenas. }\end{array}$ & $\begin{array}{l}\text { Promover programas de } \\
\text { formação e habilitação } \\
\text { específica para } \\
\text { professores que atuam } \\
\text { em educação especial, } \\
\text { nas escolas do campo, } \\
\text { nas comunidades } \\
\text { quilombolas e nas } \\
\text { indígenas, e que } \\
\text { contemplem também } \\
\text { as temáticas: educação } \\
\text { ambiental, educação } \\
\text { para os direitos } \\
\text { humanos, educação } \\
\text { integral e integrada. }\end{array}$ & $\begin{array}{l}\text { Gestores e educadores } \\
\text { capacitados para } \\
\text { educação inclusiva. }\end{array}$ & $\begin{array}{l}\text { SEESP - Programa } \\
\text { Educação Inclusiva: } \\
\text { Direito à Diversidade }\end{array}$ \\
\hline $\begin{array}{l}\text { Grau de participação } \\
\text { dos profissionais } \\
\text { de serviços e apoio } \\
\text { escolar em programas } \\
\text { de qualificação } \\
\text { específicos. }\end{array}$ & $\begin{array}{l}\text { Promover a participação } \\
\text { dos profissionais de } \\
\text { serviço e apoio escolar } \\
\text { em programas de } \\
\text { formação continuada, } \\
\text { educação integral e } \\
\text { integrada. }\end{array}$ & $\begin{array}{l}\text { Qualificação dos } \\
\text { profissionais de serviço } \\
\text { e apoio a escola para } \\
\text { atendimento aos alunos } \\
\text { em tempo integral. }\end{array}$ & $\begin{array}{l}\text { Pro-funcionário - Curso } \\
\text { Técnico de Formação } \\
\text { para os Funcionários da } \\
\text { Educação (Alimentação } \\
\text { Escolar) }\end{array}$ \\
\hline $\begin{array}{l}\text { Grau de participação } \\
\text { dos profissionais } \\
\text { de serviços e apoio } \\
\text { escolar em programas } \\
\text { de qualificação } \\
\text { específicos. }\end{array}$ & $\begin{array}{l}\text { Promover a } \\
\text { participação dos } \\
\text { profissionais de serviço } \\
\text { e apoio escolar em } \\
\text { programas de formação } \\
\text { inicial e continuada. }\end{array}$ & Não especificado & $\begin{array}{l}\text { Programa Nacional de } \\
\text { Formação Continuada a } \\
\text { Distância nas Ações do } \\
\text { FNDE - Formação pela } \\
\text { Escola. }\end{array}$ \\
\hline
\end{tabular}

Fonte: PAR-PBX (2007) 
as unidades escolares. O PAR-PBX detalha a possibilidade de desenvolvimento local dos seguintes programas federais (Quadro 3), nas áreas de:"Formação inicial de professores da educação básica”; de "Formação de professores para modalidades de ensino" ${ }^{11}$, e de "Formação do profissional de serviços e apoio escolar".

De acordo com a sistemática do PAR, as equipes técnicas locais (estaduais e municipais) podem selecionar, dentre os programas já ofertados pelo Ministério, aqueles que atendem a situações consideradas problemas no diagnóstico inicial formulado. Esses programas abrangem necessidades de sistemas de ensino, especialmente a formação profissional e, se for o caso, equipamentos e construções. Por sua vez, técnicos do Ministério da Educação avaliam a coerência entre diagnóstico, com base nos dados do Censo Escolar da Educação Básica, e os programas solicitados. Após essa análise, a decisão de assistência técnica e financeira com o comprometimento do poder público local com resultados educacionais.

Além dos governos, as escolas podem e devem, de acordo com o PAR, elaborar planos de desenvolvimento articulados ao Plano de Ações do Município. Este, por sua vez, ao elaborar o seu plano de ação, traz orientações às suas unidades escolares quanto a prioridades estabelecidas a partir do diagnóstico municipal e sobre a implementação local de programas socioeducacionais federais.

\section{0s Planos de Desenvolvimento das Escolas - PDEs-ESCOLA}

0 PDE-escola deverá ser elaborado em consonância com o Plano de Ações Articuladas do município. (Brasil/MEC, 2009c, p. 9).

Quais os temas e as ações recorrentes nos PDEs elaborados pelas escolas na cidade X e como suas propostas se articulam com o Plano de Ações do município? Para esse objetivo, foram analisados os 93 PDEs das escolas municipais

12. Para fins deste artigo, foi apresentado resumo dos resultados encontrados, com destaque para as demandas da área de gestão e das divergências entre o pedido das escolas, as demandas do PAR municipal e as prioridades programáticas do Ministério. com menor IDEB. Nestes, quais os pedidos de recursos elaborados e a justificativa apresentada aos itens solicitados ${ }^{12}$ ?

No manual de instruções para a elaboração 
do PDE-Escola, divulgado em 2006, consta que este "representa para a escola um momento de análise de seu desempenho, ou seja, de seus processos, de seus resultados, de suas relações internas e externas, de seus valores e de suas condições de funcionamento" (Brasil, 2006, p. 11). Neste documento de orientação, o PDE das escolas foi considerado como

Ferramenta gerencial que auxilia a escola a definir suas prioridades estratégicas, a converter suas prioridades em metas educacionais e outras concretas, a decidir o que fazer para alcançar as metas de aprendizagem e outras estabelecidas, a medir se os resultados foram atingidos e a avaliar 0 próprio desempenho. (Brasil, 2006, p. 20).

Nesse documento ${ }^{13}$-“Como elaborar o plano de desenvolvimento da Escola: aumentando o desempenho da escola por meio de planejamento eficaz" - o MEC informa que apenas reformulou alguns pontos do antigo manual elaborado no contexto doFundo de Fortalecimento da Escola(Fundescola) ${ }^{\mathbf{1 4}}$. Na terceira edição acrescenta:

[...] além da 'Apresentação' ter sido inteiramente reformulada, aqui e ali a redação foi alterada para esclarecer alguns pontos de mais difícil entendimento para os leitores, na edição anterior. [...] Em particular, no Instrumento 2 (ou questionário 2), os chamados "fatores de eficácia", até então em número de seis, passaram a se denominar "critérios de eficácia", tendo sido acrescentado um novo critério, o sétimo, de "Resultados". Essa modificação permitirá à escola trabalhar com mais foco e precisão nos resultados que precisa alcançar para melhor atender alunos, equipe, pais e comunidade. (Brasil, 2006, nota à 3a edição).

Embora o documento de orientação do PDE-Escola tenha mantido os procedimentos de elaboração e a concepção de gestão voltada para o cumprimento de metas e objetivos estratégicos, formulada na segunda metade da década de 90 , sob a inspiração das diretrizes do Banco Mundial, esta nova versão destaca, ainda mais, ganhos de resulta-

13. Esta publicação, chamada de Manual no seu próprio texto (p. 19), teve sua última edição em 2006 - $3^{\text {a }}$ edição. Esta edição é usada atualmente pelas equipes das escolas para elaborar seus PDEs.

14. Programa do Ministério da Educação, cofinanciado pelo Banco Mundial, voltado para as escolas das regiões Nordeste, Norte e Centro-Oeste. 0 Fundescola I teve início em junho de 1998 e a seu término em dezembro de 2010. 
dos, reforçando concepções de qualidade centradas na aferição do rendimento.

Para iniciar a elaboração do PDE-Escola, as equipes escolares devem realizar um diagnóstico de sua realidade ou análise situacional, no mesmo sistema eletrônico do Ministério. A partir desse diagnóstico, por meio de uma equipe de sistematização previamente escolhida entre os membros da comunidade escolar, é elaborado o Plano de Desenvolvimento da Escola - PDE-Escola (Brasil, 2006, p. 39). A metodologia de elaboração do PDE-Escola assemelha-se à de elaboração do PAR. Os procedimentos de formulação estabelecidos para estes dois programas educacionais aqui analisados - PDE-Escola e PAR - utilizam equipes previamente escolhidas para a elaboração e a sistematização dos planos, reforçam a importância da participação de diferentes atores, assim como dão ênfase à liderança do gestor municipal e/ou escolar na execução e no acompanhamento dos objetivos propostos. No âmbito municipal, o MEC aconselha a formação de um comitê gestor local, composto por técnicos das secretarias de educação e treinados pelo ministério para orientação e acompanhamento da proposta das escolas ${ }^{15}$. Para as escolas, a ênfase é posta na participação das comunidades escolares, mas somente após as escolas submeterem seu projeto ao Comitê Gestor Municipal e, quando aprovados por esse comitê, os pedidos de assistência técnica e/ou financeira são remetidos eletronicamente à avaliação no MEC.

As unidades escolares passaram, então, a elaborar planos de desenvolvimento a partir das orientações e dos procedimentos estabelecidos. Um primeiro formulário a ser preenchido no sistema on-line é chamado "Instrumento 1 - Perfil e funcionamento da escola”. Neste, consta registro referente às condições e à organização escolar. Um segundo formulário - “Instrumento 2: análise dos critérios de eficácia escolar” - é composto por questionário a ser respondido por todos os membros da comunidade escolar. Esse questionário solicita a avaliação da comunidade escolar, em uma escala de um a cinco, sobre os seguintes aspectos: a) Ensino e aprendizagem; b) Clima escolar; c) Pais e comunidade; d) Gestão de pessoas; e) Gestão de processos e f) Infraestrutura.

\begin{abstract}
15. A formação do comitê gestor municipal não vem estabelecida no manual de elaboração do PDE-Escola, mas ao acessar o Simec, o link de tramitação dos planos informa que estes erão enviados ao comitê gestor municipal para avaliação e ajustes, antes de serem enviados para a análise do MEC. No manual do Plano de Ações Financiáveis - PAF- encontramos também orientação quanto ao comitê gestor municipal.
\end{abstract}

A filiação aos princípios normativos constantes nos estudos relacionados à eficácia escolar é explícita nesse documento. Entretanto, o documento possibilita aos técnicos do Ministério da Educação a análise da relação existente em cada escola entre sua organização pedagógica e os resultados 
alcançados. Esta relação evidencia-se na etapa final de elaboração - "requisitos e características a serem atacadas prioritariamente" -, quando o formulário estabelece apenas dois critérios obrigatórios a serem selecionados pelas escolas: "ensino e aprendizagem" e "resultados". Após o preenchimento dos quatro formulários constantes no modelo do PDE-escola, o procedimento final envolve o preenchimento dos planos de ação - Plano de Suporte Estratégico -, em que deverão constar as ações previstas e os recursos financeiros necessários. Entretanto, essa demanda deve ater-se aos itens de despesa previstos no Plano de Ações Financiáveis - $\mathrm{PAF}^{16}$ - e nem todos os objetivos estratégicos traçados pelas escolas se acham articulados a itens financiáveis pelo MEC.

Evidência complementar nesse sentido foi obtida no decorrer do campo de pesquisa, quando os pesquisadores foram informados de que a demanda inicial formulada pela comunidade da escola - recursos para serviços de marcenaria - foi recusada.

Ação 1: PAF não financia contratação de empresa para design de móveis. Sugerimos a retirada da ação ou que a Secretaria Municipal de Educação ou outro parceiro financie esta ação. Ou ainda por meio dos recursos do PDDE Escola. Ação 2 - PAF não financia construção de armários, mas somente pequenos reparos e construções para o PROINF0 E OU ACESSIBILIDADE; o que não é o caso. Sugerimos a retirada da ação. (Fonte: PDE-escola, Escola $\mathrm{X}$, 2009). ${ }^{17}$

Para esta análise, foram considerados os planos de ação que fundamentaram as

16. Disponivel em: http://portal.mec.gov.br/seb/arquivos/pdf/paf_pde_esc.pdf. Acessado em: 16/03/2011 17. Resposta encaminhada ao Comitê gestor municipal por técnico do MEC a respeito de solicitação da escola, quando datramitação do PDE-escola no Simec. 


\section{Quadro 4 - Itens selecionados pelas escolas e financiáveis na parcela principal estabelecida pelo Ministério da Educação}

\begin{tabular}{|c|c|c|}
\hline \multirow{2}{*}{ ITENS DEMANDADOS COMO DESPESA DE CUSTEIO } & \multicolumn{2}{|c|}{ ESCOLAS SOLICITANTES } \\
\hline & NÚMERO & $\%$ \\
\hline 1.1. Material de apoio pedagógico & 86 & 92,5 \\
\hline 1.2. Material de laboratório & 9 & 9,7 \\
\hline 1.3. Material esportivo & 37 & 39,8 \\
\hline $\begin{array}{l}\text { 1.4. Material de apoio às atividades do } \\
\text { acompanhamento pedagógico - } \\
\text { Programa Mais Educação; }\end{array}$ & 4 & 4,3 \\
\hline $\begin{array}{l}\text { 1.5. Material de apoio às atividades sobre meio } \\
\text { ambiente - Programa mais Educação }\end{array}$ & 1 & 1,1 \\
\hline $\begin{array}{l}\text { 1.6. Material de apoio às atividades de esporte e } \\
\text { lazer - programa Mais Educação; }\end{array}$ & 2 & 2,2 \\
\hline $\begin{array}{l}\text { 1.7. Material de apoio às atividades de cultura e arte } \\
\text { - programa Mais Educação; }\end{array}$ & 7 & 7,5 \\
\hline 1.8. Assinatura de periódicos e anuidades; & 33 & 35,5 \\
\hline 1.9. Manutenção e conservação de equipamento; & 7 & 7,5 \\
\hline $\begin{array}{l}\text { 1.10. Contratação de serviços para comunicação } \\
\text { em geral; }\end{array}$ & 6 & 6,5 \\
\hline $\begin{array}{l}\text { 1.11. Contratação de serviços para formação dos } \\
\text { profissionais da escola para: palestras, cursos, } \\
\text { seminários, workshops; }\end{array}$ & 83 & 89,2 \\
\hline $\begin{array}{l}\text { 1.12. Serviços de monitoria do programa } \\
\text { Mais Educação; }\end{array}$ & 15 & 16,1 \\
\hline $\begin{array}{l}\text { 1.13. Contratação de serviço de informática, instalação } \\
\text { de equipamento, pequenas construções, reparos na } \\
\text { rede elétrica e hidráulica e instalações físicas; }\end{array}$ & 21 & 22,5 \\
\hline 1.14. Contratação de serviços gráficos; & 65 & 69,9 \\
\hline 1.16. Contratação de serviço de transporte. & 55 & 59,1 \\
\hline $\begin{array}{l}\text { 1.17. Contratação de serviços para montagem de } \\
\text { armários, murais, etc; }\end{array}$ & 13 & 14,0 \\
\hline $\begin{array}{l}\text { Total de demandas relacionadas a custeio e de } \\
\text { escolas pesquisadas }\end{array}$ & 433 & 93 \\
\hline
\end{tabular}

Fonte:PDE-escola de 93 escolas municipais, 2009. 
parcelas principais recebidas pelas escolas municipais da cidade X. Posteriormente, algumas escolas receberiam uma nova parcela de recursos do PDE-Escola denominada "parcela complementar". De acordo com a classificação dos itens financiáveis, os PDEs das 93 escolas analisadas apresentaram as seguintes demandas de recursos em custeio:

Demandas por materiais didáticos, os mais diversos, no item de consumo, são reveladoras da situação de infraestrutura pedagógica existente nas escolas ${ }^{18}$. A essas demandas acrescentam-se, ainda, os serviços relacionados às atividades de informática e pequenos consertos. Todas as escolas analisadas, como mencionado, apresentaram re-

\begin{tabular}{|c|c|c|}
\hline $\begin{array}{l}\text { OBJETIVOS ESTRATÉGICOS } \\
\text { RECORRENTES }\end{array}$ & METAS ASSOCIADAS & $\begin{array}{l}\text { No DE OCORRÊNCIAS } \\
\text { NOS PDES-ESCOLA }\end{array}$ \\
\hline \multirow{7}{*}{$\begin{array}{l}\text { A. ELEVAR } 0 \text { DESEMPENHO } \\
\text { ACADÊMICO }\end{array}$} & 1) elevar resultado do IDEB & 13 \\
\hline & $\begin{array}{l}\text { 2) elevar resultados medidos } \\
\text { pela escola }\end{array}$ & 28 \\
\hline & $\begin{array}{l}\text { 3) adotar projetos de } \\
\text { intervenção pedagógica }\end{array}$ & 35 \\
\hline & $\begin{array}{l}\text { 4)reelaborar o projeto político } \\
\text { pedagógico e o currículo }\end{array}$ & 38 \\
\hline & $\begin{array}{l}\text { 5) investir na formação/ } \\
\text { capacitaçãode professores }\end{array}$ & 27 \\
\hline & $\begin{array}{l}\text { 6) investir em novas práticas } \\
\text { pedagógicas, metodologias }\end{array}$ & 62 \\
\hline & $\begin{array}{l}\text { 7)adquirir materiais/ } \\
\text { equipamentos }\end{array}$ & 37 \\
\hline \multirow{2}{*}{$\begin{array}{l}\text { B. CONSTRUÇÃO DO PROJETO } \\
\text { POLÍTICO PEDAGÓGICO/ } \\
\text { PROPOSTA PEDAGÓGICA/ } \\
\text { ORGANIZAÇÃO ESCOLAR }\end{array}$} & $\begin{array}{l}\text { 1) reformular a proposta } \\
\text { pedagógica }\end{array}$ & 21 \\
\hline & 2) reestruturar o plano curricular & 15 \\
\hline $\begin{array}{l}\text { C. MELHORIAS NA DEPENDÊNCIA } \\
\text { DA ESCOLA }\end{array}$ & 1) investir no clima escolar & 18 \\
\hline \multirow{2}{*}{$\begin{array}{l}\text { D. INCENTIVO ÀPARTICIPAÇÃO } \\
\text { DA FAMÍLIA E DA COMUNIDADE }\end{array}$} & 1) elevar os resultados & 14 \\
\hline & 2) melhorar o clima escolar & 32 \\
\hline $\begin{array}{l}\text { E. MELHORAR } \\
\text { A GESTÃO DA ESCOLA }\end{array}$ & 1) capacitar a equipe escolar & 19 \\
\hline
\end{tabular}

Fonte: Plano de Ação/PDE-escola de 93 escolas municipais, 2009. 
sultados medidos pelo IDEB abaixo das médias nacional, estadual e municipal, mas priorizaram suas demandas para materiais pedagógicos, e a formação profissional (Quadro 4).

Às demandas de custeio, acrescidas das demandas de capital, estão associados objetivos estratégicos e metas a serem alcançados, reafirmados no plano das escolas.

\section{Quadro 4 - Objetivos mais recorrentes nos PDEs- escola da rede municipal/2009}

O objetivo explícito do Ministério da Educação, de elevação do rendimento do aluno/desempenho escolar medido pelo IDEB, é incorporado no documento de planejamento das escolas municipais de $X$ consideradas mais vulneráveis. Entretanto, estas, ao elaborarem seus PDEs, associaram, ao objetivo de melhoria do desempenho, meios necessários às atividades de ensino-aprendizagem. Os PDEs-escola analisados reiteram que a existência de meios adequados é condição necessária para a melhoria do desempenho.

A sistemática de planejamento constante no PAR possibilita às escolas liberdade na escolha dos meios necessários, porém ao flexibilizar escolhas, orienta demandas por recursos. Se contempla a diversidade de situações existente entre as escolas, porém restringe em função de procedimentos predeterminados na elaboração dos planos e da escolha dentro de um leque preestabelecido de recursos. Fonseca (2009) e Toschi e Oliveira (2004, p. 197) enfatizam que, embora o PDE-escola tenha como premissa assegurar a autonomia escolar, estabelece "estratégias de cunho gerencial, normativo e centralizador".

\section{Modos de regulação dos sistemas educacionais e o sistema federativo brasileiro}

Como mencionado pelo Ministério da Educação para a justificação do PAR:

0 Plano de Metas Compromisso Todos pela Educação, instituído pelo Decreto 6.094 de 24 de abril de 2007, é um programa estratégico do $\mathrm{PDE}$, e inaugura um novo regime de colaboração, que busca concertar a atuação dos entes federados sem lhes ferir a autonomia, envolvendo primordialmente a decisão política, a ação técnica e atendimento da de- 
manda educacional, visando à melhoria dos indicadores educacionais. Trata-se de um compromisso fundado em vinte e oito diretrizes e consubstanciado em um plano de metas concretas, efetivas, que compartilha competências políticas, técnicas e financeiras para a execução de programas de manutenção e desenvolvimento da educação básica. A partir da adesão ao Plano de Metas do PDE, os estados, os municípios e o Distrito Federal passaram à elaboração de seus respectivos Planos de Ações Articuladas (PAR). (Brasil, 2009a, p. 2, grifo nosso).

A ação da União diretamente com os municípios, sem a intermediação dos estados subnacionais, passou a orientar a elaboração de planos municipais de educação e de suas escolas. Essa interação direta objetiva a operacionalização do regime de colaboração - previsto constitucionalmente - entre os entes federados e a articulação de ações com vistas à melhoria do desempenho educacional medido pelo IDEB. A disseminação do Plano de Ações Articuladas contribui para maior protagonismo da União na coordenação dos demais sistemas de ensino, ou, como menciona Barroso (2006), na metarregulação sistêmica.

Sistemas públicos de políticas sociais universais desenvolveram-se, especialmente nos países europeus, mediante regulamentação de procedimentos que efetivam direitos. Nessas situações, a prescrição normativa requeria aos atores envolvidos a conformidade e a observação da norma. No entanto, a sistemática do PAR convida-os à melhoria da qualidade da educação aferida pelo IDEB, mediante o consentimento ativo (Duarte, 2009) das equipes locais na produção de soluções a situações consideradas como intervenientes sobre o desempenho.

[0 PAR e o PDDE] são ações implantadas pela União que atingem escolas e redes municipais "por fora" da esfera estadual. Utilizam o significativo poder indutor desta para implantar políticas, princípios de gestão, enfim, práticas de seu interesse. Não se pode negar que o objetivo é alcançado, particularmente nas redes menores, onde mesmo montantes muito pequenos de recursos podem impactar. Da mesma forma, quando a União formula proposições claras, tem grande capacidade de induzir outros entes federados, mesmo sem investimentos de monta. Vale, pois, um olhar mais cuidadoso sobre esses mecanismos. (Oliveira e Sousa, 2010, p.23). 
O planejamento educacional disponibilizado no Simec é expressivo da ocorrência de mudanças nos modos de regulação das relações intergovernamentais e dos sistemas de ensino. Verifica-se, simultaneamente, tentativa de estabelecer maior racionalidade entre meios e fins na relação do poder público local com suas escolas e deste com o governo central. Por intermédio da sistemática proposta para elaboração do PAR, a União constrange e incentiva agentes públicos a lógicas de ação voltadas para resultados. Trata-se da disseminação do modo de regulação por desempenho (Maroy, 2006) em um país em que relações de cunho neoclientelistas são ainda predominantes.

Este estudo, por sua vez, argumentou que prioridades a serem desenvolvidas, desde a divulgação do Plano de Desenvolvimento da Educação em 2007, envolvem a efetivação de relações intergovernamentais diretas entre União, municípios e escolas, sob a égide do ente federado central. Coube à União a indução de ações, capazes de promover melhores resultados educacionais, e o mecanismo de indução por excelência, envolve as transferências de recursos mediante assistência técnica e financeira. Não se trata da seleção de projetos elaborados de forma autônoma pelas escolas ou por sistemas municipais. O elemento de credibilidade de programas e projetos da União é impulsionado pela crítica e pela atuação discricionária de dirigentes locais e pela reduzida eficácia na prestação dos serviços que asseguram o direito à educação. Desse modo, a elaboração do PAR pelos municípios e do PDE pelas escolas reforça, além da articulação de ações locais pela lógica do desempenho, o papel de coordenação sistêmica ou de regulação institucional do sistema educacional no País, sem uma regulamentação prévia do regime de colaboração.

A disseminação de lógicas de ação voltada para melhores resultados educacionais é legitimada pela associação direta entre medidas de aferição e qualidade educacional, enquanto valor a ser perseguido. Para que essa nova racionalidade percorra o território brasileiro, sistema eletrônico de coleta de informações e de monitoramento das ações de âmbito nacional intervém nas relações entre os entes federados, impulsionado pela possibilidade de transferência de recursos.

Mas o incentivo a ações previamente prescritas (de matriz burocrática) acha-se, também, materializado no sistema on-line de solicitação da assistência do Ministério da Educação (Simec). Mediante procedimentos preestabelecidos para diagnóstico e planejamento das ações educacionais no âmbito do município (PAR) e das escolas (PDE-escola), esse ambiente virtual requer, dos sistemas locais, o fortalecimento da atuação profissional das equipes técnicas municipais e escolares na gestão educa- 
cional. Atuação mais profissionalizada para a fundamentação da escolha de procedimentos, ações e gestão dos recursos financeiros, sempre condicionados ao alcance de metas e resultados educacionais, convive de modo tenso entre os atores presentes na gestão dos sistemas de ensino e das escolas. Sob o discurso legitimador da melhoria da qualidade, a prescrição de ações educacionais formuladas vai ao encontro das demandas estabelecidas por atores locais e as ressignificam.

A disseminação da elaboração de Planos de Ações Articuladas, a nosso ver, expressaria mudança política na regulação dos atores e das ações educacionais governamentais, em que o Estado brasileiro, especialmente a União, rearticula seus procedimentos de implementação de políticas públicas para o sistema educacional brasileiro, com o objetivo de coordená-lo mediante a participação de diferentes atores governamentais e não governamentais. Essa reorientação envolve, também, a "focalização" ou a "territorialização" das ações, sempre que necessário, em espaços sociais específicos, e a participação de múltiplos atores na direção de maior controle social, enquanto recurso para responsabilização dos agentes políticos ${ }^{19}$.

A União, mediante mecanismos e dispositivos inseridos no PAR, passaria a ter força relevante para influenciar políticas locais, além das regras institucionais que orientam relações intergovernamentais. Se a disputa por recursos públicos (materiais, técnicos ou financeiros) constitui o centro da formulação de políticas públicas, a análise destas no campo educacional procura articular medidas aparentemente isoladas no interior de um movimento mais amplo de mudança institucional e das formas de sociabilidade política.

19. Sobre a noção de controle social em gestão da educação, ver: Duarte e Faria, 2006. 


\section{Referências bibliográficas}

ALVES. F. Qualidade da educação fundamental: integrando desempenho e fluxo escolar. Ensaio: avaliação, políticas, públicas e Educação, Rio de Janeiro, v. 15, n. 57, p. 525-542, out. / dez. 2007.

AZEVEDO, J. M. L. de. Implicações da nova lógica de ação do Estado para a educação municipal. Educação e Sociedade, Campinas, v. 23, n. 80, p. 49-71, set. 2002.

BALL, S. J. Reformar escolas/ reformar professores e os terrores da performatividade. Revista Portuguesa de Educação, Braga, (PT), v.15, n. 02, p. 03-23, 2002.

BALL, S. J. Performatividade, privatização e o pós-estado do bem-estar. Educação e Sociedade, Campinas, v. 25, n. 69, p. 1105-1126, set./dez. 2004. Disponível em:www. cedes.unicamp.br. Acesso em: 13 out. 2009.

BARROSO, J. A regulação das políticas públicas de educação: espaços, dinâmicas e atores. Lisboa: Educa, 2006.

BARROSO, J. O Estado, a educação e a regulação das políticas públicas. Educação $e$ Sociedade, Campinas, v. 26, n. 92, p. 725-751, out. 2005.

BRASIL. Ministério da Educação. Como elaborar o plano de desenvolvimento da escola: aumentando o desempenho da escola por meio do planejamento eficaz. 3. ed. Brasília: FUNDESCOLA/ DIPRO/ FNDE/MEC, 2006. 201p.

BRASIL. Decreto no 6094, de 24 de abril de 2007. Dispõe sobre a implementação do Plano de Metas Compromisso Todos pela Educação, pela União Federal, em regime de colaboração com Municípios, Distrito Federal e Estados, e a participação das famílias e da comunidade, mediante programas e ações de assistência técnica e financeira, visando a mobilização social pela melhoria da qualidade da educação básica. Disponível em: www.mec.gov.br. Acesso em: 28 ago. 2010.

BRASIL. Ministério da Educação. Guia prático de ações. Brasília, 2009c. p. 1-82. Disponível em: www.mec.gov.br. Acesso em: 28 ago. 2010.

BRASIL. Ministério da Educação. Manual técnico operacional do Módulo de Monitoramento do Plano de Ações Articuladas - PAR. Brasília, 2009b. p. 1-20. Disponível em: www.mec.gov.br. Acesso em: 2 ago. 2010.

BRASIL. Ministério da Educação. Orientações gerais para elaboração do Plano de Ações Articuladas (PAR) dos Municípios. ed. revisada e ampliada. Brasília, 2009a. p. 1-54. Disponível em: www.mec.gov.br. Acesso em: 28 ago. 2010.

BRASIL. Ministério da Educação. O Plano de Ações financiáveis do PDE - Escola. Disponível em: http://portal.mec.gov.br/seb/arquivos/pdf/paf_pde_esc.pdf. Acesso em: 20 jan. 2011. 
BRASIL. Ministério da Educação. PDE- escola 2010: orientações gerais. 32p.

BRASIL. Ministério da Educação. Sinopse das ações do Ministério da Educação. Brasília, 2010. Disponível em: www.mec.gov.br. Acesso em: 18 dez. 2010.

BRASIL. Ministério da Educação. Plano de Metas Compromisso Todos pela Educação: Plano de ações articuladas - PAR. Brasília, 2008a. 10p. Disponível em: www.mec.gov. br. Acesso em: 28 ago. 2010.

BRASIL. Ministério da Educação. Plano de Metas Compromisso Todos pela Educação: instrumento de campo. Brasília, 2008(b). p. 1-43. Disponível em: www.mec.gov.br. Acesso em: 28 ago. 2010.

BRASIL. Ministério da Educação. PDE - Plano de Desenvolvimento da Educação: Prova Brasil - Ensino Fundamental: matrizes de referência, tópicos e descritores. Brasília: MEC, SEB, INEP, 2008c.

BROOKE, N.; SOARES, J. F. (Org.). Pesquisa em eficácia escolar: origem e trajetórias. Tradução de Viamundi Idiomas. Traduções de Cleusa Aguiar Brooke e Rômulo Monte-Alto. Belo Horizonte: Editora UFMG, 2008. 552p.

CURY, C. R. J. Sistema Nacional de Educação: desafio para uma educação igualitária e federativa. Educação e Sociedade, Campinas, v. 29, n. 105, p. 1187-1209, set./dez. 2008.

DUARTE, M. R. T. A produção do consentimento ativo e os padrões de oferta: reflexões a partir da implementação do Projovem. In: DUARTE, M. R. T. (Org.) Palavras de jovens sobre o Projovem: estudos com egressos e a formação de pesquisadores em avaliação de programas educacionais. Belo Horizonte: Escritório de Histórias, 2009. p. 199-228.

DUARTE, M. R. T. Regulação sistêmica e política de financiamento da educação básica. Educação e Sociedade, Campinas, v. 26, n. 92, p. 821-839, out. 2005.

DUARTE, M. R. T. Sistemas públicos de educação básica e relações intergovernamentais: a ação da União e a autonomia dos sistemas locais de ensino. Perspectiva: Revista do Centro de Ciências da Educação - Universidade Federal de Santa Catarina, Centro de Ciências da Educação, Florianópolis: Editora da UFSC: NUP/ CED, v. 20, n. 2, jul./dez. 2002. p. 303-327.

DUARTE, M. R. T.; FARIA, G. G. Regulación del sistema educacional en Brasil, control social y vinculación de recursos con la educacación. In: FELDFEBER, M.; O., D. A. (Org.). Políticas educativas y trabajo docente: nuevas regulaciones? Nuevos sujetos? Buenos Aires: Centro de Publicaciones Educativas y Material Didáctico, 2006. 
FONSECA, M. Políticas públicas para a qualidade da educação brasileira: entre o utilitarismo econômico e a responsabilidade social. Cadernos CEDES, Campinas, v.29, n.78, p. 153-177, ago. 2009.

FRANCO, C.; ALVES, F.; BONAMINO, A. Qualidade do ensino fundamental: políticas, suas possibilidades, seus limites. Educação e Sociedade, Campinas,v. 28, n.100, p. 989-1014, out. 2007.

HADDAD, F. O plano de desenvolvimento da Educação: razões, princípios e programas. Brasília: Instituto Nacional de Estudos e Pesquisas Educacionais Anísio Teixeira, 2008. 23p.

IVO, A. A.; HYPOLITO, A. M.O Plano de Desenvolvimento da Educação: uma análise no contexto escolar. In: REUNIÃO ANUAL DA ANPED, 33. Trabalho do GT 05: Estado e Política Educacional. Caxambu, 2009. 16p.

KRAWCZYK, N.R. O PDE: novo modo de regulação estatal? Cadernos de Pesquisa, São Paulo, v. 38, n. 135, p. 797-815, set./ dez. 2008.

MAROY, C. École, régulation et marché: une comparaison de six espaces scolarires locaux en Europe. Paris: Presse Universitaire de France, 2006.

MAROY, C. Régulation des systems éducatifs. In: ZANTEN, A.V. Dictionnaire de l'éducation, Quadrige/ PUF, Paris, sep., 2008. p. 574-578.

MAROY, C. Une comparaison des formes de régulation intermédiaire dans cinq pays européens. In: DUTERCQ Y.(Ed.). Les régulations des politiques d'éducation. Rennes: Presses Universitaires de Rennes, 2005.

NASCIMENTO, C. G. do. Brasil.- Plano de Desenvolvimento da Educação: para início de conversa. Adital: notícias da América Latina e Caribe, Brasil, 29 out. 2007. Disponível em: http://www.adital.com.br/. Acesso em: 14 dez.2010.

OLIVEIRA, R. P. de. Da universalização do ensino fundamental ao desafio da qualidade: uma análise histórica. Educação e Sociedade, Campinas, v. 28, n.100, p. 661-690, out. 2007.

OLIVEIRA, R. P. de. Estado e política educacional no Brasil: desafios do século XXI. 2006. 106f. Tese (Livre-Docência em Educação) - Faculdade de Educação, Universidade de São Paulo, São Paulo, 2006.

ROSANVALLON, P. La légitimité démocratique - Impartialité, réfléxivité, proximité. Paris: Seuil, 2008.

SAVIANI, D. O plano de desenvolvimento da educação: análise do projeto do MEC. Educação e Sociedade, Campinas, v. 28, n. 100p. 1231-1255, out. 2007. Especial. Disponível em: http://www.cedes.unicamp.br. Acesso em: 24 nov. 2010. 
SOLANO, C. H. O Plano de desenvolvimento da Educação e Plano de Desenvolvimento da Escola: desdobramentos da implementação dessas políticas na gestão escolar. In: CONGRESSO IBERO-LUSO-BRASILEIRO DE POLÍTICA E ADMINISTRAÇÃO DA EDUCAÇÃO. Trabalho do GT Políticas locais e gestão escolar. Elvas (Portugal); Cáceres (Espanha), 2010. p.1-14.

SORDI, M.R.L.; LUDKE, M. Da avaliação da aprendizagem à avaliação institucional: aprendizagens necessárias. Avaliação, Campinas; Sorocaba, v.14, n. 2, p.313-336, jul. 2009.

TOSCHI, M. S; OLIVEIRA, J. F. (Org.). Escolas gerenciadas: planos de desenvolvimento e projetos político-pedagógicos em debate. Goiânia: Editorada UCG, 2004. 219p.

TOSCHI, M. S.; OLIVEIRA, J. F. O programa Fundescola: concepções, objetivos, componentes e abrangência - a perspectiva de melhoria da gestão do sistema e das escolas públicas. Educação e Sociedade, Campinas, v. 26, n. 90, p. 127-147, jan./ abr. 2005.

VIEIRA, L. M. F. Plano de desenvolvimento: o "PAC" da educação. Revista Pensar BH/ Política Social, Belo Horizonte, p. 5-7. jun./ ago. 2007.

WEBER, S. Relações entre esferas governamentais na educação e o PDE: o que muda? Cadernos de Pesquisa, São Paulo, v. 38, n. 134, p. 305-318, maio/ago. 2008.

Submetido à publicação em 21 de dezembro de 2011.

Versão final aprovada em 24 de setembro de 2012. 